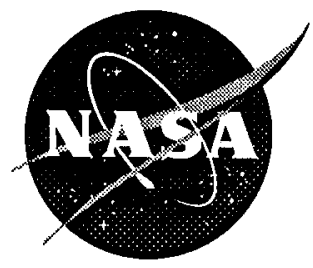

\title{
Linear Aerospike SR-71 Experiment (LASRE): Aerospace Propulsion Hazard Mitigation Systems
}

Masashi Mizukami, Griffin P. Corpening,

Ronald J. Ray, Neal Hass, and Kimberly A. Ennix

Dryden Flight Research Center

Edwards, California

Scott M. Lazaroff

NASA Johnson Space Center

Houston, Texas

National Aeronautics and

Space Administration

Dryden Flight Research Center

Edwards, California 93523-0273

July 1998 


\section{NOTICE}

Use of trade names or names of manufacturers in this document does not constitute an official endorsement of such products or manufacturers, either expressed or implied, by the National Aeronautics and Space Administration.

Available from the following:

NASA Center for AeroSpace Information (CASI) 7121 Standard Drive

Hanover, MD 21076-1320

(301) 621-0390
National Technical Information Service (NTIS) 5285 Port Royal Road Springfield, VA 22161-2171 (703) $487-4650$ 


\title{
LINEAR AEROSPIKE SR-71 EXPERIMENT (LASRE): AEROSPACE PROPULSION HAZARD MITIGATION SYSTEMS
}

\author{
Masashi Mizukami, ${ }^{*}$ Griffin P. Corpening, ${ }^{\dagger}$ Ronald J. Ray, ${ }^{\dagger}$ Neal Hass, ${ }^{\dagger}$ Kimberly A. Ennix ${ }^{\dagger}$ \\ NASA Dryden Flight Research Center \\ Edwards, California \\ Scott M. Lazaroff ${ }^{\dagger}$ \\ NASA Johnson Space Center \\ Houston, Texas
}

\begin{abstract}
$\underline{\text { Abstract }}$
A major hazard posed by the propulsion system of hypersonic and space vehicles is the possibility of fire or explosion in the vehicle environment. The hazard is mitigated by minimizing or detecting, in the vehicle environment, the three ingredients essential to producing fire: fuel, oxidizer, and an ignition source. The Linear Aerospike SR-71 Experiment (LASRE) consisted of a linear aerospike rocket engine integrated into one-half of an X-33-like lifting body shape, carried on top of an SR-71 aircraft. Gaseous hydrogen and liquid oxygen were used as propellants. Although LASRE is a one-of-a-kind experimental system, it must be rated for piloted flight, so this test presented a unique challenge. To help meet safety requirements, the following propulsion hazard mitigation systems were incorporated into the experiment: pod inert purge, oxygen sensors, a hydrogen leak detection algorithm, hydrogen sensors, fire detection and pod temperature thermocouples, water misting, and control room displays. These systems are described, and their development discussed. Analyses, ground test, and flight test results are presented, as are findings and lessons learned.

\section{Nomenclature}

canoe aerodynamically-shaped pod, housing fluid and other systems in LASRE

$\mathrm{GH}_{2} \quad$ gaseous hydrogen

$\mathrm{H}_{2} \quad$ hydrogen

${ }^{*}$ Aerospace Engineer, AIAA Member.

${ }^{\dagger}$ Aerospace Engineer.

Copyright (c) 1998 by the American Institute of Aeronautics and Astronautics, Inc. No copyright is asserted in the United States under Title 17, U.S. Code. The U.S. Government has a royalty-free license to exercise all rights under the copyright claimed herein for Governmental purposes. All other rights are reserved by the copyright owner.
\end{abstract}

$\mathrm{H}_{2} \mathrm{O} \quad$ water

$\mathrm{He}$ helium

LASRE Linear Aerospike SR-71 Experiment

$L N_{2} \quad$ liquid nitrogen

$\mathrm{LO}_{2} \quad$ liquid oxygen

model top portion of LASRE, shaped like onehalf of a lifting body

$N_{2} \quad$ nitrogen

$\mathrm{O}_{2} \quad$ oxygen

$P \quad$ hydrogen tank pressure, psi

$P_{a m b} \quad$ ambient pressure, psia

$P_{\text {calib }} \quad$ pressure during calibration, psia

psi pounds per square inch

psia pounds per square inch, absolute

psig pounds per square inch, gage

$P_{S L} \quad$ sea level pressure, psia

$R \quad$ gas constant

$T \quad$ hydrogen gas temperature, $\mathrm{R}$

TEA-TEB triethylaluminum-triethylborane

$V \quad$ hydrogen tank volume, in $^{3}$

Z $\quad$ compressibility

$\Delta m_{H_{2}} \quad$ change in mass of hydrogen in tanks, lbm

$\% \mathrm{H}_{2} \quad$ volume fraction of hydrogen

$\% \mathrm{H}_{2 \text { meas }}$

$\% \mathrm{O}_{2}$

$\% \mathrm{O}_{2 \text { meas }}$ volume fraction of hydrogen, measured

volume fraction of oxygen

volume fraction of oxygen, measured 


\section{Introduction}

For hypersonic and space vehicles that are reusable or piloted, safety is an exceptionally important consideration. For piloted vehicles, this consideration is a result of the possible tragic consequences of a mishap. For reusable launch vehicles, cost is the major driver; the total operational costs must be minimized, including the high cost of losing an expensive vehicle and its payload as a result of a mishap. For a flight research project, safe flight can be considered as important as the technology being investigated.

A major hazard posed by the propulsion system of hypersonic and space vehicles is the possibility of a fire or explosion in the vehicle environment. These systems store a large amount of potential energy in the form of fuel, oxidizer, high pressures or a combination of these. ${ }^{1,2}$ The three ingredients essential to the production of fire are fuel, oxidizer, and an ignition source (except in the case of hypergolics and pyrophorics, which can combust without an ignition source). Minimizing or detecting those three ingredients in the vehicle environment mitigates the hazard. In addition to sound design and operational practices, it is often necessary to provide dedicated hazard mitigation systems.

The Linear Aerospike SR-71 Experiment (LASRE) is a flight experiment of a reusable launch vehicle propulsion concept done in cooperation with the industry. NASA Dryden Flight Research Center, Edwards, California was responsible for the flight test. ${ }^{3}$ The experiment consisted of a linear aerospike rocket engine integrated into one-half of an X-33-like lifting body shape, carried on top of an SR-71 aircraft (figs. 1, 2). Unlike conventional bell nozzle rockets, the linear aerospike engine can compensate for ambient backpressure effects to provide higher performance over a wide range of altitudes. However, external flow slipstream effects on the nozzle flow may reduce performance. Therefore, the primary objective of LASRE was to evaluate flight effects on aerospike engine performance at several altitudes and Mach numbers. Although LASRE is a one-of-a-kind experimental system, it had to be rated for piloted flight, which demands a high degree of safety. A rapid prototyping approach was taken to hardware development. This approach resulted in an extended series of tests to troubleshoot and validate the integrated system. These tests included various functional tests such as 'cold flows' of inert fluids, 'ignition tests' using $\mathrm{LO}_{2}$ and triethylaluminum-triethylborane (TEA-TEB), and actual 'hot fires' of the engine.

A simplified schematic of fluid systems in the LASRE pod is shown in figure 3. Essentially, this was a flying rocket engine test facility. The model is the top portion shaped like half of a lifting body. The canoe is an

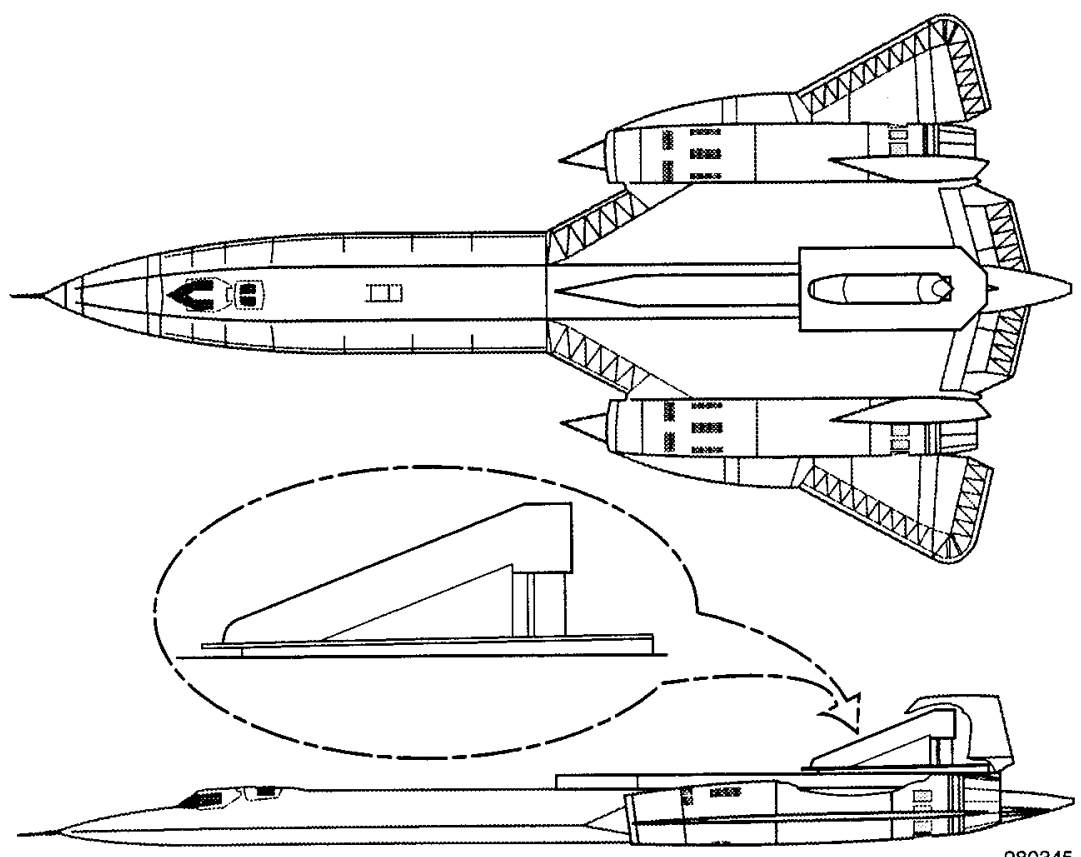

Figure 1. LASRE configuration mounted on SR-71 aircraft. 


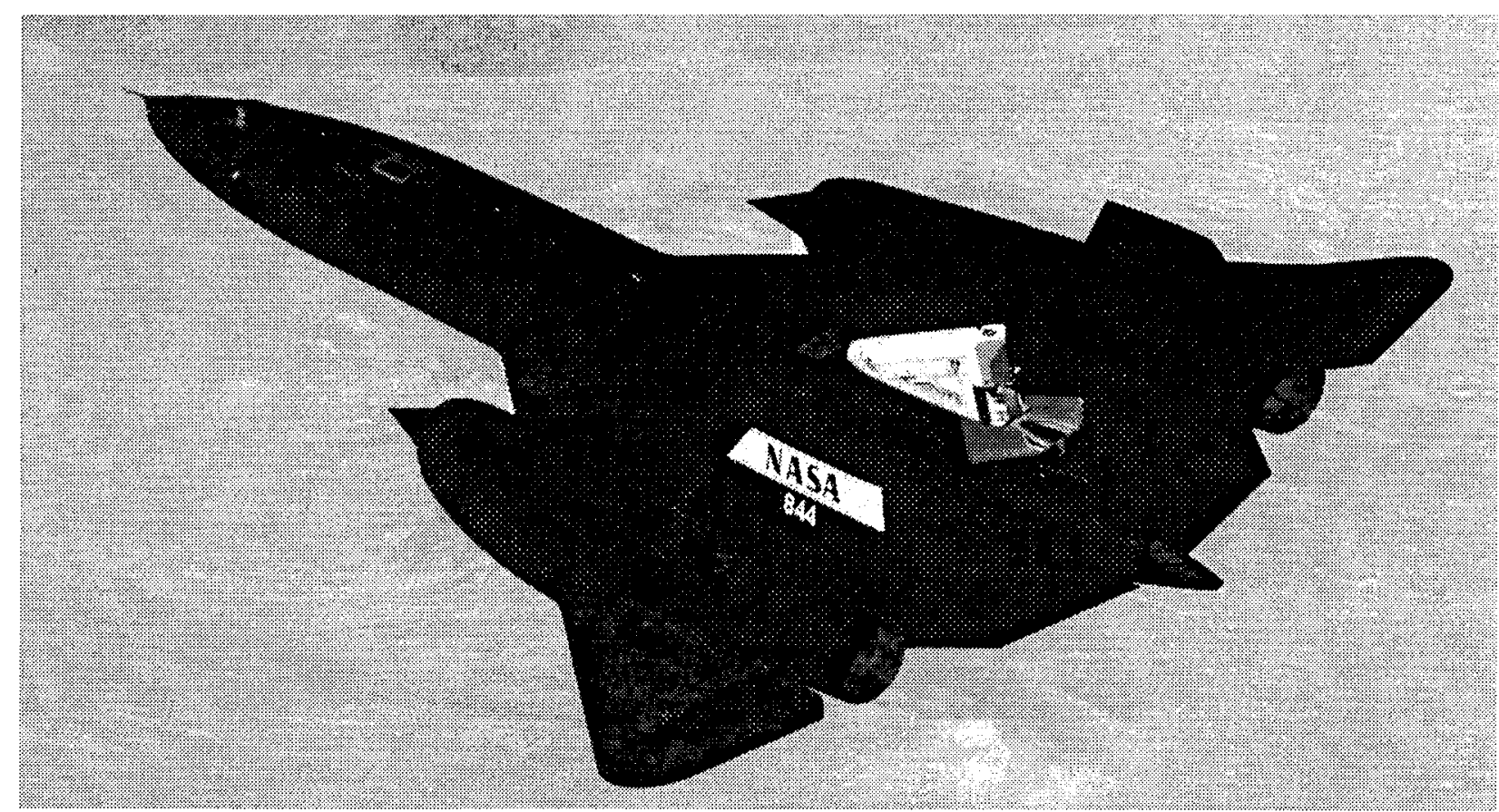

EC $97-44295-108$

Figure 2. SR-71 and LASRE in flight.

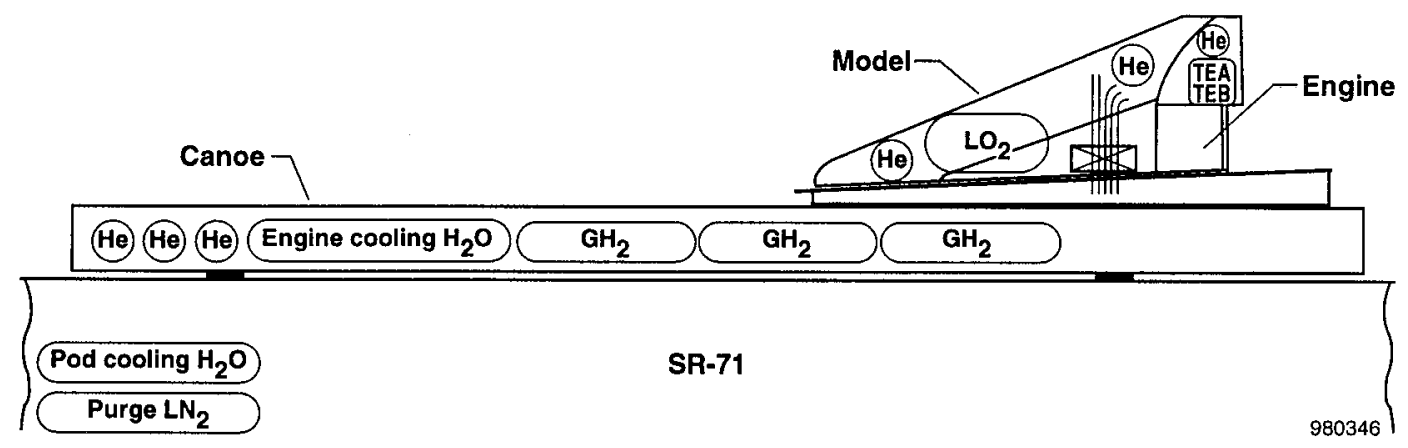

Figure 3. Simplified schematic of LASRE fluid systems.

aerodynamically-shaped pod, housing several fluid (and other) systems. A 4000 psi gaseous hydrogen $\left(\mathrm{H}_{2}\right)$ blowdown system, containing about $20 \mathrm{lb}$ of $\mathrm{H}_{2}$, provided fuel to the engine. A liquid oxygen $\left(\mathrm{LO}_{2}\right)$ system, containing about $330 \mathrm{lb}$ of $\mathrm{LO}_{2}$, and pressurized to about $365 \mathrm{psi}$, provided the oxidizer. Both $\mathrm{H}_{2}$ and $\mathrm{LO}_{2}$ could be dumped overboard through the engine. $\mathrm{H}_{2}$ could also be expelled overboard through dump lines, and $\mathrm{LO}_{2}$ pressure could be released through a vent line. Triethylaluminum-triethylborane (TEA-TEB), a pyrophoric, was used to initiate combustion in the engine. Engine coolant water, pressurized to $800 \mathrm{psi}$, flowed through channels drilled in the engine block and out the water exit line. Two 9000 psi gaseous helium $\left(\mathrm{He}\right.$ ) systems provided $\mathrm{LO}_{2}$ pressurant, water pressurant, line purges, TEA-TEB cartridge expulsion and pneumatic valve actuation. The SR-71 contained water for pod misting, and liquid nitrogen $\left(L N_{2}\right)$ for pod inert purge.

Even before hazard mitigation systems were incorporated, the soundness of the underlying propulsion system itself had to be assured. The system was intended to be fail-safe for single-point failures. Component burst and proof factors were equal to or greater than those used in typical missile and space 
systems. ${ }^{4}$ The $\mathrm{H}_{2}$ and $\mathrm{LO}_{2}$ systems were leak checked as much as was feasible on the integrated pod, using long-term pressure decay, bubble fluid, an ultrasonic leak detector, a thermal conductivity leak detector, an electrochemical hydrogen sensor, and blowdown testing.

Flammability limits for $\mathrm{H}_{2}-\mathrm{O}_{2}-\mathrm{N}_{2}$ mixtures at sea level are about 4 percent $\mathrm{H}_{2}$ and 4 percent $\mathrm{O}_{2}$, and are fairly independent of each other (fig. 4). The limits remained about the same throughout the LASRE flight envelope, extending up to an altitude of $50,000 \mathrm{ft}$, and were not significantly narrowed by reduced pressures at those altitudes. ${ }^{5}$ Calculation of combustion conditions at equilibrium or for detonation showed that even for low flammable concentrations of $\mathrm{H}_{2}$ and $\mathrm{O}_{2}$, temperatures and pressures high enough for catastrophic consequences could develop. Therefore, a ground rule was established that $\mathrm{O}_{2}$ and $\mathrm{H}_{2}$ concentrations in the pod should be maintained below 4 percent during the entire mission, because any combustion in the pod was considered unacceptable.

To help meet safety requirements, propulsion hazard mitigation systems were incorporated in LASRE. These systems were: a pod inert purge, $\mathrm{O}_{2}$ sensors, a $\mathrm{H}_{2}$ leak detection algorithm, $\mathrm{H}_{2}$ sensors, fire detection and pod temperature thermocouples, water misting, and control room displays. These systems are described, and their development discussed. Analyses, ground test, and fight test results are presented, as are findings and lessons learned. Use of trade names or names of manufacturers in this document does not constitute an official endorsement of such products or manufacturers, either expressed or implied, by the National Aeronautics and Space Administration.

\section{Propulsion Hazard Mitigation Systems}

The following sections discuss the systems and methods used to mitigate propulsion hazards. Findings and lessons learned as a result of tests performed are also presented.

\section{Pod Inert Purge}

The pod cavity was purged with inert $N_{2}$ gas, for several reasons. The primary purpose was to minimize the presence of oxidizer in the pod environment to below 4 percent $\mathrm{O}_{2}$ by displacing air out of the pod. The purge may also reduce the presence of fuel by displacing any leaked $\mathrm{H}_{2}$. The $\mathrm{H}_{2}$ and $\mathrm{LO}_{2}$ valves and some of the electronics boxes were purged with $N_{2}$, to minimize ignition sources. This purge surrounded the electronics with inert gas, and prevented moisture caused by water misting from coming into contact with the electronics.

Figure 5 shows a schematic of the $N_{2}$ purge system. $N_{2}$ was supplied from two $L N_{2}$ Dewar flasks onboard

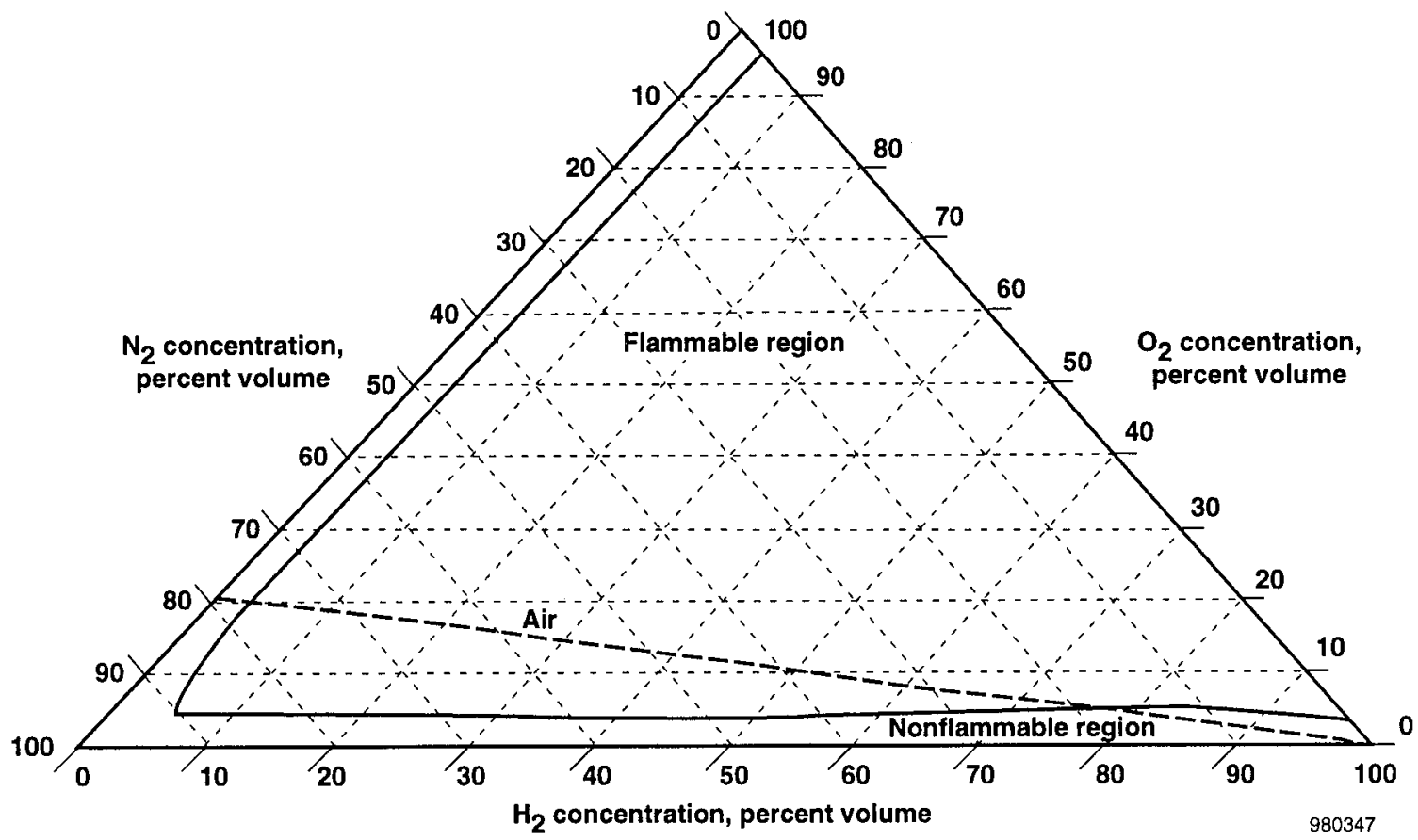

Figure 4. Flammability limits of $\mathrm{H}_{2}-\mathrm{O}_{2}-\mathrm{N}_{2}$ mixtures at sea level. 


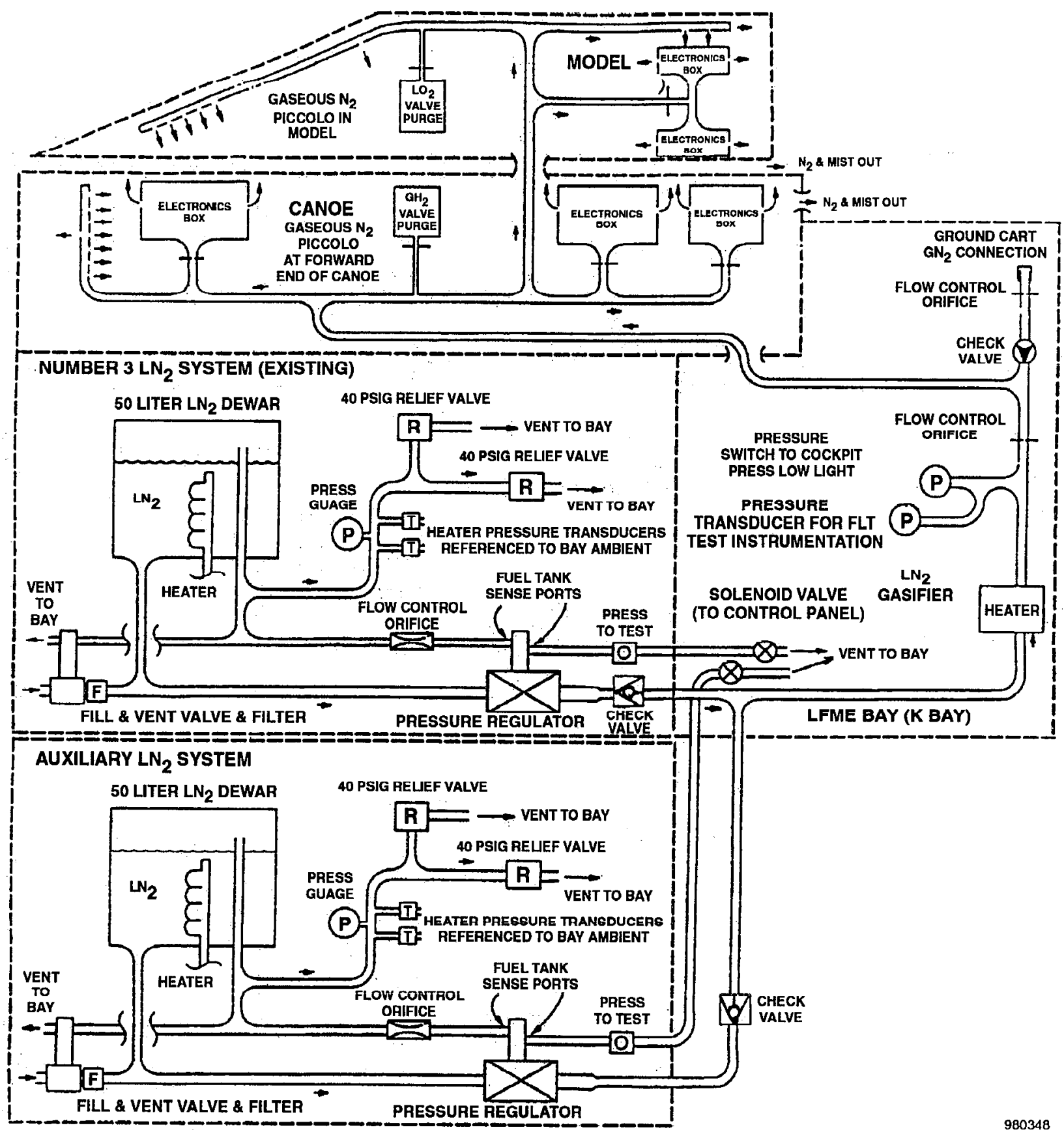

Figure 5. Nitrogen purge system schematic. 
the SR-71. $L N_{2}$ was vaporized by electric heaters, it was dispersed into the pod through perforated piccolo tubes near the front of the pod, and also into the electronics boxes and valves. The two Dewar flasks held a total of 100 liters $(180 \mathrm{lb})$ of $L N_{2}$. The flow rate was about $2.5 \mathrm{lb} / \mathrm{min}$, or 34 standard cubic feet per minute, for an operating duration of 72 minutes. These flow rates gave about 0.3 volume change-outs per minute on the ground, and 2.4 change-outs per minute at an altitude of $50,000 \mathrm{ft}$. For ground operations, $N_{2}$ was directly provided from a ground cart to conserve the onboard $\mathrm{LN}_{2}$ supply. During flight, flow could be turned on or off from the SR-71 rear cockpit, and the operating pressure was monitored in the control room to verify flow.

Purge effectiveness was evaluated primarily by using $\mathrm{O}_{2}$ sensors distributed in the pod. Preliminary ground testing revealed that it took a long time to establish a purged environment, and the pod panels had to be wellsealed to maintain it. Therefore, a separate monster purge was implemented to establish an initially purged environment by using ground service equipment that fed large quantities of $N_{2}$ directly into the pod. During subsequent ground tests an adequate purge was confirmed. In flight however, substantial infiltration of external air occurred shortly after takeoff and purge effectiveness was quickly lost, with $\mathrm{O}_{2}$ levels reaching nearly 21 percent. Therefore, attempts were made to seal gaps in the pod by using elastic materials such as foam rubber and caulking. Also, the second $L N_{2}$ Dewar flask was added, and purge flow rate was doubled to current levels $(2.5 \mathrm{lb} / \mathrm{min})$. In addition, a valve was placed in the purge vent line, which could be remotely actuated from the cockpit. With the valve open, the purge gas flowed through the pod and out the vent as originally designed, which also allowed any major leaks to be vented out of the pod. With the valve closed, the purge gas maintained a positive pressure in the pod, thus reducing air infiltration. The purge gas flowed out from any remaining leak paths. A subsequent flight test demonstrated adequate purge performance for flight, up to about Mach 0.9 and an altitude of $26,000 \mathrm{ft}$, with $O_{2}$ levels below 4 percent. Figure 6 shows Mach number, altitude, and the measured $\mathrm{O}_{2}$ levels during a portion of the flight. The canoe $\mathrm{O}_{2}$ sensor that reads consistently low $\mathrm{O}_{2}$ levels is located close to a purge piccolo tube near the front of the canoe. The spike above 4 percent is believed to be telemetry noise. A preliminary assessment of additional data suggested that purge integrity may be maintained up to Mach 1.6 and an altitude of $50,000 \mathrm{ft}$. It was observed that with the vent valve closed, pressure was maintained in the pod during climb and descent. During climb, ambient pressure decreased, and pod pressure was maintained above ambient pressure, which aided purge effectiveness. However, during descent the opposite effect occurred, which made it difficult to maintain an adequate purge. These tests demonstrated that it is important to provide an adequate purge flow rate, and to seal the vehicle well against outside air infiltration.

\section{Oxygen Sensors}

Twelve oxygen sensors were located in the pod to detect the presence of oxidizer, eight in the canoe and four in the model. The purpose of these sensors was to determine inert purge effectiveness, infiltration of outside air, and the presence of any leaked $\mathrm{LO}_{2}$. Commercially available electrolytic sensors were used, originally intended for automotive applications. Each sensor was installed in a temperature-controlled canister which was heated to about $115^{\circ} \mathrm{F}$, to reduce effects of ambient temperature changes on the readings. These sensors were point measurements that would not detect air or oxygen which could have been trapped in other areas, but the number and distribution of the sensors were judged sufficient to characterize overall $\mathrm{O}_{2}$ levels in the pod.

It was evident from data at altitude that these sensors actually measured the partial pressure of $\mathrm{O}_{2}$, but volume fraction is of greater interest than partial pressure for determining the flammability of mixtures. Therefore, volume fraction of $\mathrm{O}_{2} \quad\left(\% \mathrm{O}_{2}\right)$ was calculated by correcting the measured partial pressure of $\mathrm{O}_{2}\left(\% \mathrm{O}_{2 \text { meas }}\right)$ to sea level pressure $\left(P_{S L}\right)$, using ambient pressure $\left(P_{a m b}\right)$, as follows:

$$
\% \mathrm{O}_{2}=\% \mathrm{O}_{2_{\text {meas }}} \frac{P_{S L}}{P_{a m b}}
$$

Accuracy of the sensor at sea level, according to the specification sheet, was 1 percent. But for a given volume fraction of $\mathrm{O}_{2}$, as altitude increased, ambient pressure decreased, and the partial pressure of $\mathrm{O}_{2}$ decreased, approaching sensor accuracy limits. As a result, at high altitudes $\mathrm{O}_{2}$ volume fraction determined from sensor readings appeared erratic.

A test program was undertaken to better characterize sensor accuracy at altitude. In a small test chamber, sensors were exposed to a range of $\mathrm{O}_{2}$ concentrations varying from 0 percent to 21 percent, at a range of pressure altitudes from sea level to $80,000 \mathrm{ft}$. Because sensors have a life of about 2 years, new sensors as well as older ones were tested to help determine aging 

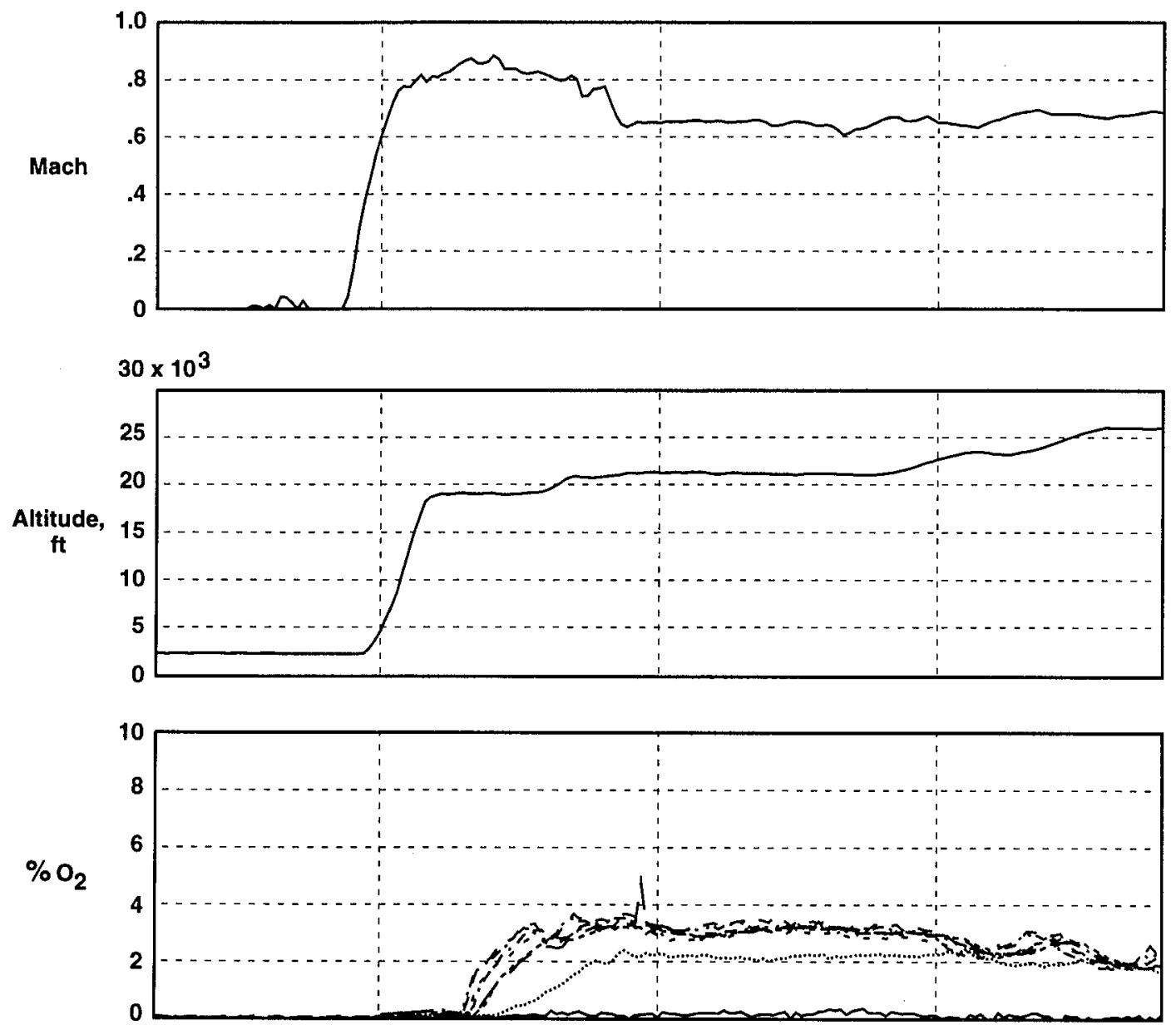

Canoe $\mathrm{O}_{2}$ sensors

...... $--$

- - -

$-\cdot \cdot-\cdot$

$-$

-...-

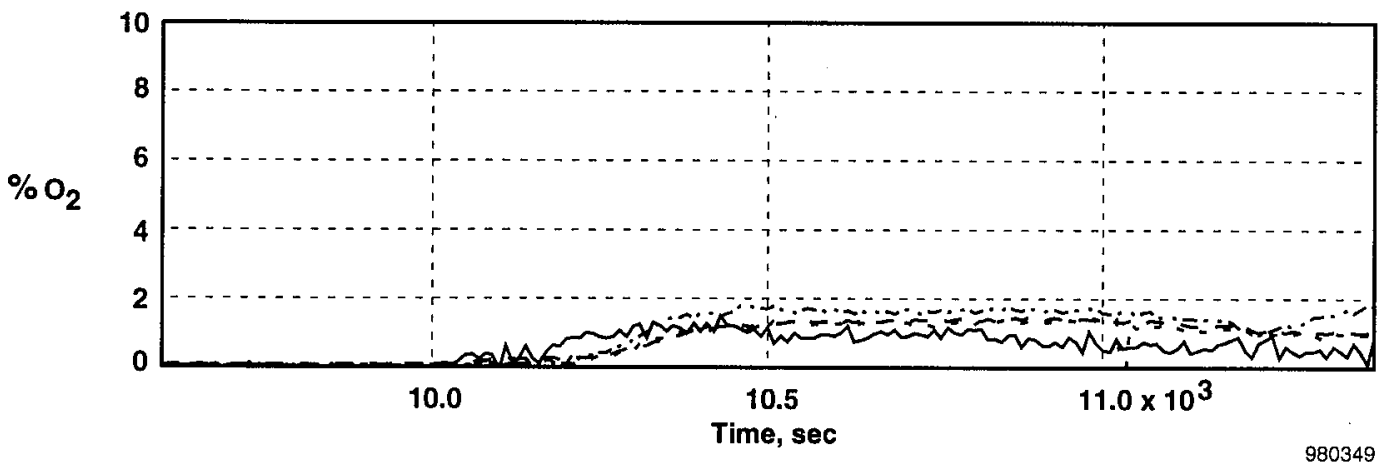

Model $\mathrm{O}_{2}$ sensors

..... - -

$-\cdots$

Figure 6. Nitrogen purge effectiveness in flight, from takeoff up to Mach 0.9 and an altitude of $26,000 \mathrm{ft}$. 
effects. Representative results for 0 percent, 1 percent, 2 percent and 5 percent $\mathrm{O}_{2}$ concentrations are shown in figure 7(a). Accuracy at sea level appears much better than the specified 1 percent accuracy, but a distinct drop-off is seen above an altitude of $30,000 \mathrm{ft}$. To compensate for the drop-off, a fifth-order polynomial correction was applied to the average of the sensor readings (fig. 7(b)). Ninety-nine percent confidence intervals for the corrected readings, based on the t-distribution, were less than 1.3 percent up to an altitude of 50,000 ft (fig. 7(c)).

Rules were established for interpreting and acting on $\mathrm{O}_{2}$ sensor data during flight. If any $\mathrm{O}_{2}$ sensor, plus its uncertainty, exceeded a specified threshold level (nominally 4 percent), steps would be taken to secure the system and mitigate the hazard, typically by dumping the $\mathrm{H}_{2}$ overboard.

Clearly, it was important to validate $\mathrm{O}_{2}$ sensor accuracy before use, especially because these sensors were being used outside their originally intended environment. Characteristics of other types of sensors, or sensors from other manufacturers, might be entirely different.

\section{Hydrogen Pressure Decay Leak Detection}

In order to infer the presence of fuel in the pod, a real-time pressure-decay method was used to detect leaking hydrogen. Conventionally, pressure-decay leak detection takes a long time to perform, and is done during system checkout. A noticeable pressure drop in the gaseous hydrogen tanks during flight operation would indicate a large leak, or perhaps a thermal transient. However, as a result of the unavailability of hydrogen sensors, a pressure-decay method was implemented for real time in-flight use. It was for detection of leaks from the $\mathrm{H}_{2}$ tanks in a static mode only, and not for detection of leaks in the $\mathrm{H}_{2}$ lines or during flow.

In theory, the hydrogen tank leak rate can be determined from the change in mass of hydrogen in the tanks $\left(\Delta m_{H_{2}}\right)$ as follows:

$$
\Delta m_{H_{2}}=\frac{V}{R}\left(\frac{P}{Z T}-\frac{P_{0}}{Z_{0} T_{0}}\right)
$$

Tank pressure $(P)$ was measured by a pressure transducer. Hydrogen gas temperature $(T)$ was measured by two redundant thermocouples mounted on probes

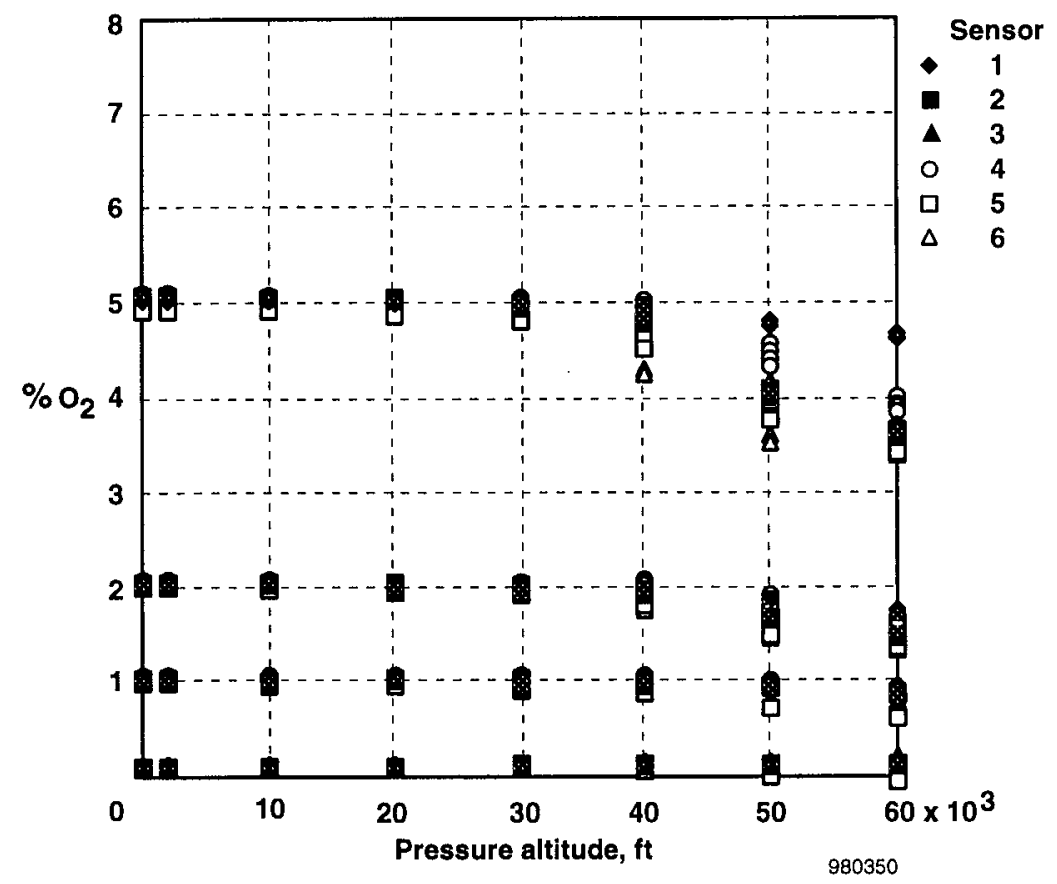

(a) Pressure altitude compared with percent $O_{2}$, for 5 percent, 2 percent, 1 percent and 0 percent $O_{2}$ mixtures.

Figure 7. Oxygen sensor altitude chamber test data. 


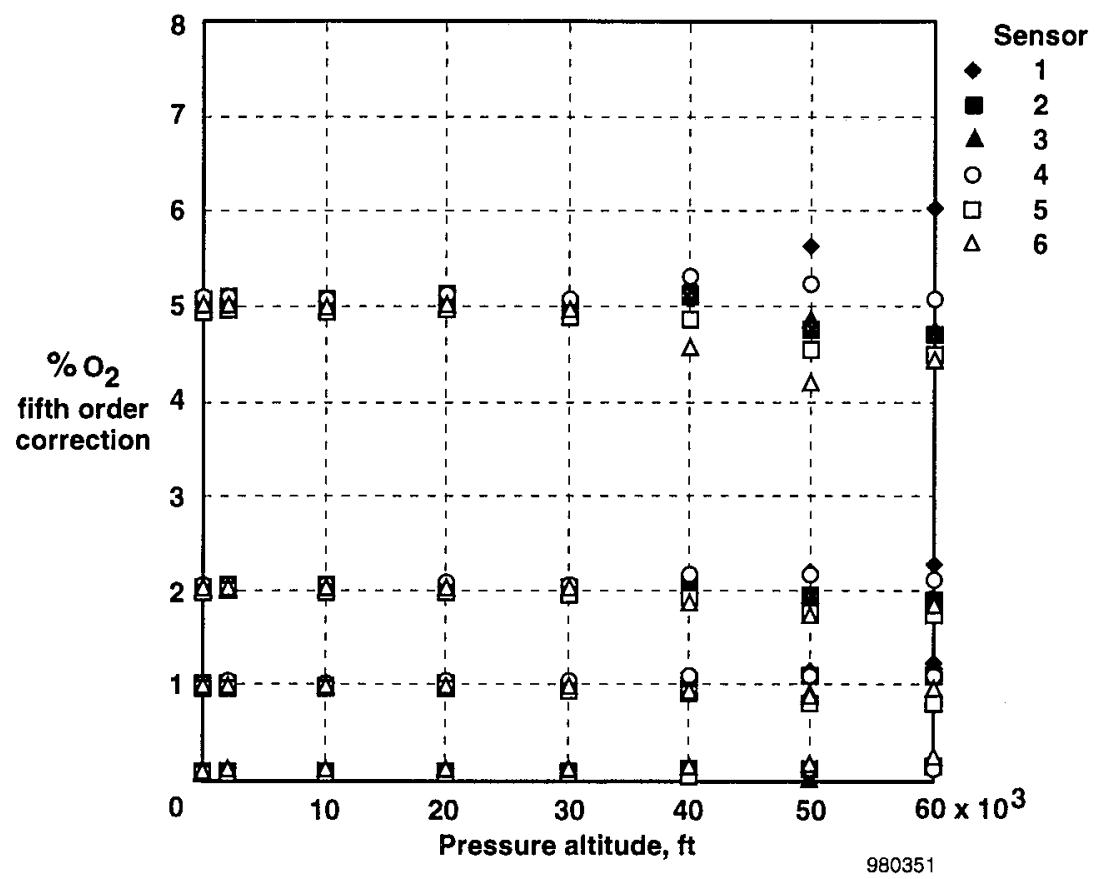

(b) Pressure altitude compared with percent $O_{2}$ with fifth order correction, for 5 percent, 2 percent, 1 percent and 0 percent $\mathrm{O}_{2}$ mixtures.

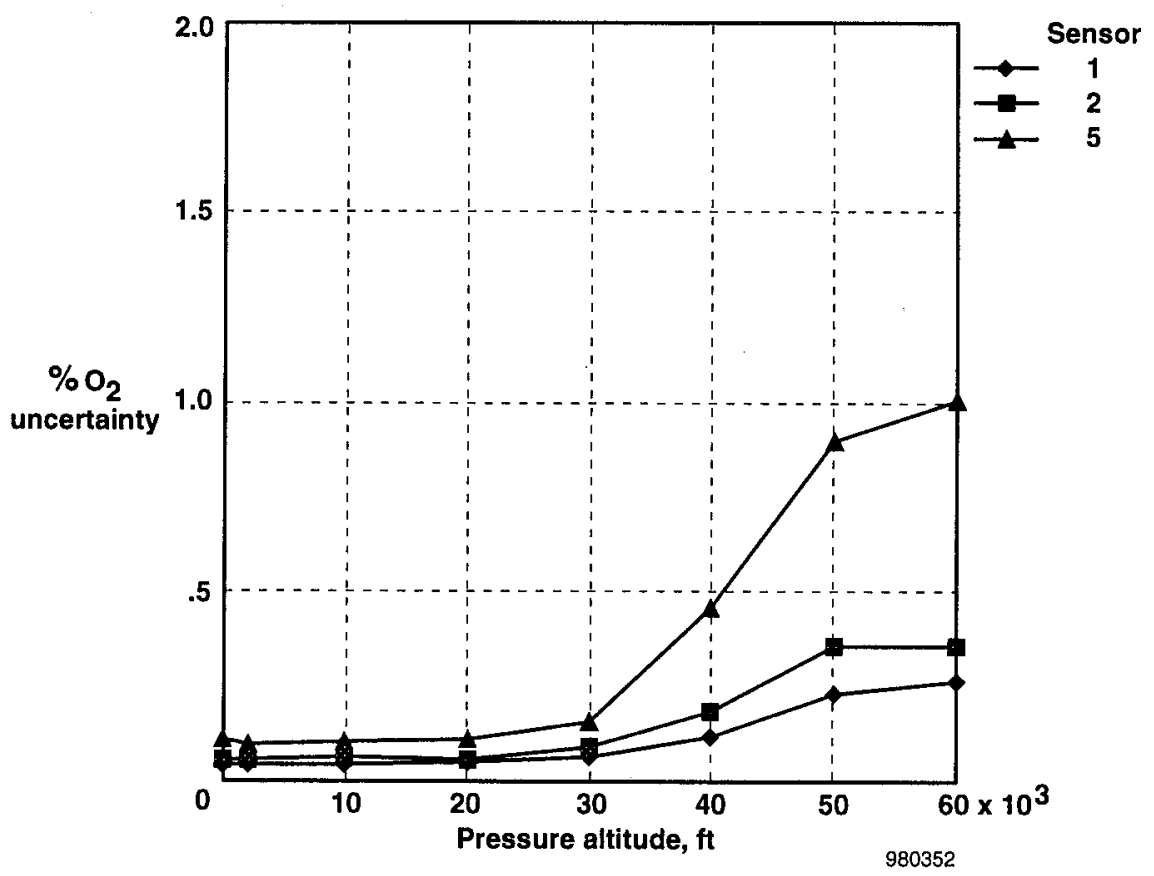

(c) Pressure altitude compared with 99 percent confidence intervals for 5 percent, 2 percent and 1 percent $O_{2}$ mixtures.

Figure 7. Concluded. 
inside the tanks, which were averaged together. Note, that to obtain an accurate measurement of gas temperature under changing conditions, a tank surface measurement would have been inadequate. Tank volume $(V)$ was assumed to be constant. Compressibility (Z) was a function of $P$ and $T$, and the subscript 0 denotes initial conditions. $R$ is the gas constant for $\mathrm{H}_{2}$.

In software, digital low-pass filtering was applied to the $\Delta m_{H_{2}}$ signal, to remove high frequency random noise, and to facilitate data interpretation. The filter time constant was adjustable, and was set by the user to obtain a readable signal, while preserving reasonable response time and quick recovery from data spikes. Magnitude limits were imposed to prevent telemetry data spikes from corrupting the calculation. The calculation could be configured for either hydrogen or inert helium as the working gas. The resulting $\Delta m_{H_{2}}$ signal was displayed on a scrolling time history display (fig. 8).

The ability to detect leaks depended on discerning small changes in pressure and temperature, which was a function of instrumentation accuracy. The trace showed good stability under the varying ambient conditions of flight. Uncertainty analysis indicated that a mass loss of $0.15 \mathrm{lb}$ or more could be detected. Ground testing, done by releasing controlled small amounts of gas from the tanks and observing the trace, showed that mass loss as low as $0.03 \mathrm{lb}$ could be detected.

In the control room, if a mass loss rate of greater than $0.03 \mathrm{lb}$ was seen in 8 minutes or less, it would be considered a positive determination of leakage, and steps would be initiated to secure the system by dumping propellants overboard. This leak rate corresponds to about 4 percent of the $\mathrm{N}_{2}$ purge flow rate in the vicinity of the $\mathrm{H}_{2}$ tanks, or about 1460 standard cubic inches per minute. This amount was judged to be the minimum leak rate reliably detectable in a reasonable timeframe. However, this is still a substantial and potentially hazardous quantity of hydrogen that is capable of locally forming combustible mixtures in the pod. Lower leak rates could possibly be detected over a longer period of time.

The $\mathrm{H}_{2}$ leak detection algorithm was a useful tool and was the only available means of $\mathrm{H}_{2}$ leak detection on LASRE, but could not be relied upon to detect all hazardous leaks. This algorithm could detect moderate to large tank leaks, or smaller leaks over a long period of time. However, it could not detect small but still hazardous leaks in a timely manner, nor did it detect leaks in the $\mathrm{H}_{2}$ lines.

\section{Hydrogen Sensors}

Although $\mathrm{H}_{2}$ sensors were not used, they would have constituted a more direct way to detect the presence of fuel. Sensors were planned to be strategically positioned within the canoe and model. The sensor proposed for use was based upon a design developed by Sandia National Laboratories, Albuquerque, New Mexico. ${ }^{6}$ The sensor element was a Palladium-Nickel patch that has a current passing through it. When present, hydrogen freely infiltrates the lattice network of the crystal, causing a change to the electrical resistance of the element proportional to the local concentration. The element was temperature regulated by a controller, which aided in the response time of the sensor and removed one of the operational variables. The advertised range of detection was 1 percent to 100 percent volume fraction, with 0.5 percent accuracy.

The suitability and accuracy of the sensor in a flight environment needed to be ascertained. A test chamber was used to simulate pressure altitudes. Testing was conducted with pure $N_{2}$ and with calibration gases of specific concentrations of $\mathrm{H}_{2}$ in $\mathrm{N}_{2}$, at discrete ambient

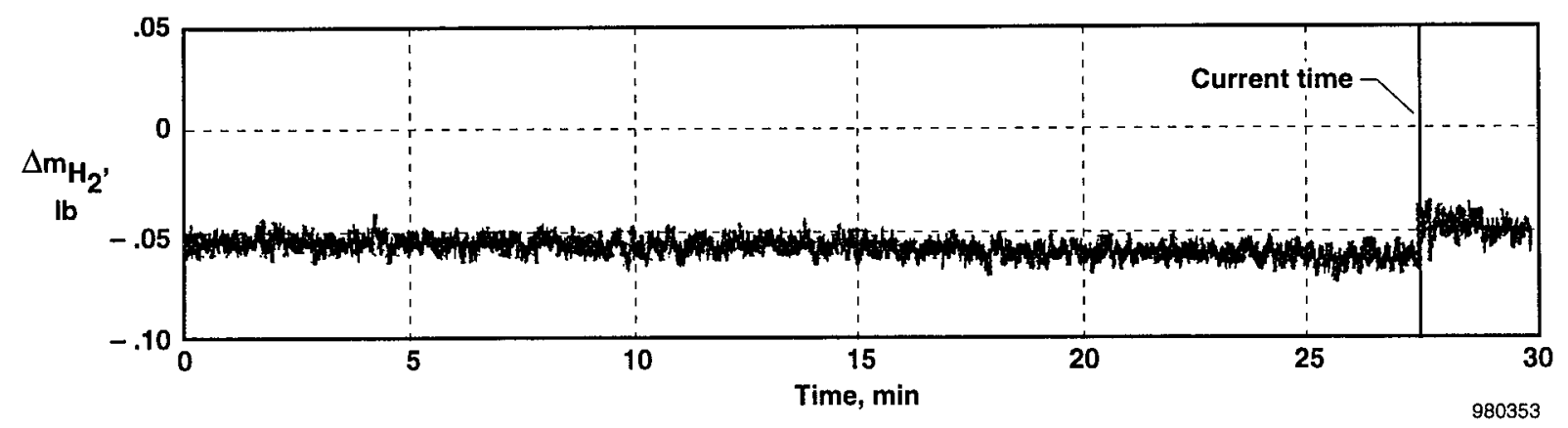

Figure 8. Hydrogen tank leak detection algorithm scrolling time history plot display. 
pressure points ranging from 2 psia to 13.5 psia. The sensor heating element mitigated temperature effects.

Preliminary data for seven sensors with a 3 percent $\mathrm{H}_{2}$ concentration by volume are shown in figure 9 (a). It is clear from the data that when the ambient pressure was reduced the sensor measured concentration was also lowered and a linear relationship existed between ambient pressures and the measured concentration. Therefore, the $\mathrm{H}_{2}$ sensors appear to measure partial pressure of the gas to be detected, much like the $\mathrm{O}_{2}$ sensors. If this phenomenon was not accounted for, and the sensor readings $\left(\% \mathrm{H}_{2_{\text {meas }}}\right)$ were used without correction during flight, the readings could potentially lead to the false conclusion that the flammability limits had not yet been reached. Like the $\mathrm{O}_{2}$ sensors, the following correction algorithm could be applied realtime during flight using ambient pressure measurements $\left(P_{a m b}\right)$ in the pod and the pressure at which the sensors were calibrated $\left(P_{\text {calib }}\right)$, to obtain percent volume of hydrogen $\left(\% \mathrm{H}_{2}\right)$ present.

$$
\% H_{2}=\% H_{2_{\text {meas }}} \frac{P_{\text {calib }}}{P_{a m b}}
$$

Results of applying this simple correction to the raw data are shown in figure 9(b). Stable readings were seen up to nearly $27,000 \mathrm{ft}$ pressure altitude. Deviation from 3 percent actual concentration indicates a bias error, but it was believed this could be corrected with a more rigorous calibration program. Above an altitude of $27,000 \mathrm{ft}$, the accuracy limitation of the sensor is reflected in the nonlinear deviation and data scatter. Very similar results where achieved using a 10 percent $\mathrm{H}_{2}$ concentration.

Unfortunately, once installed in the pod, the system could not be made to function correctly, apparently because of design flaws in the $\mathrm{H}_{2}$ sensor controller. Programmatic and schedule constraints ruled out the possibility of troubleshooting to correct the system, so the $\mathrm{H}_{2}$ sensors were not installed for flight.

Certainly, a $\mathrm{H}_{2}$ detection system would be highly desirable for hazard mitigation. Bench test results were promising for future flight applications. However, $\mathrm{H}_{2}$ sensors and systems that are qualified for use in inert background, with varying pressures and temperatures and that are robust and compact enough for flight application are difficult to find. ${ }^{7,8} \mathrm{H}_{2}$ detection technologies can be pursued for future projects, as this type of fuel becomes more prevalent.

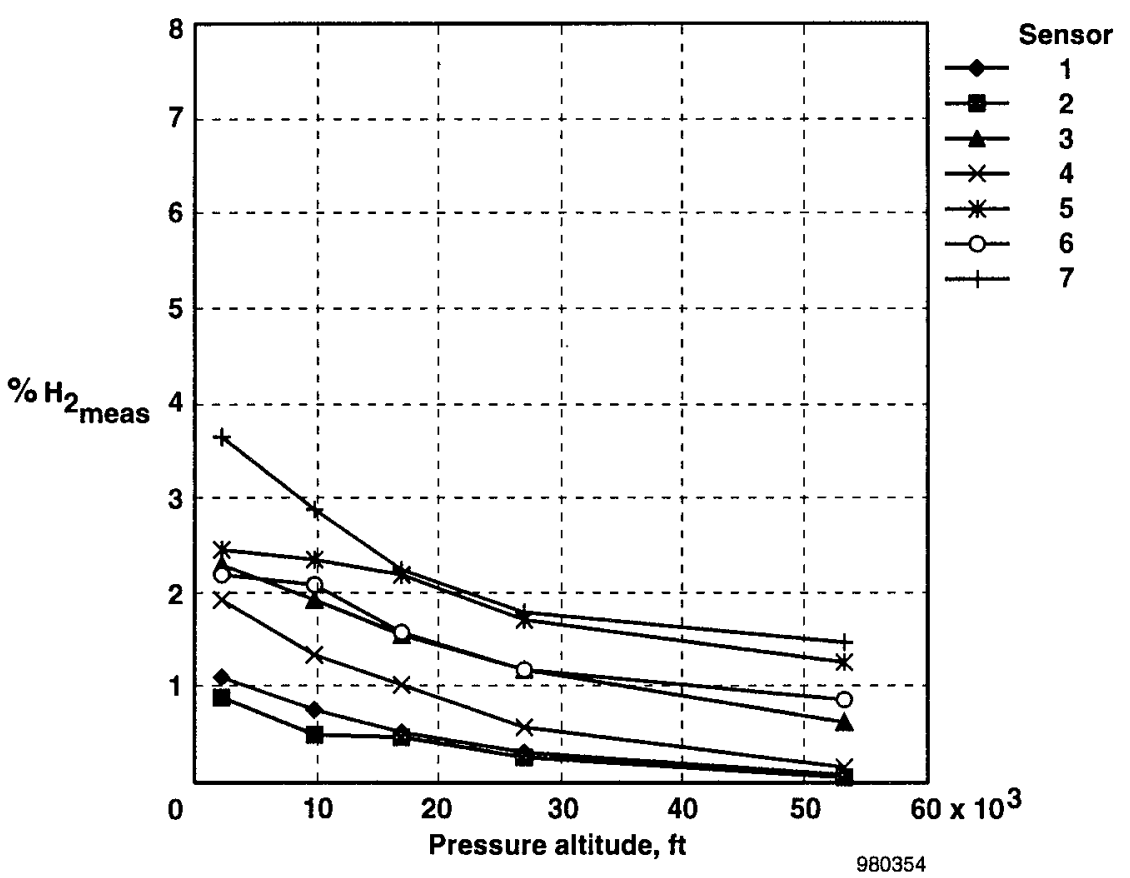

(a) Pressure altitude compared with percent $\mathrm{H}_{2}$ measured, for 3 percent $\mathrm{H}_{2}$ mixture.

Figure 9. Hydrogen sensor altitude chamber test data. 


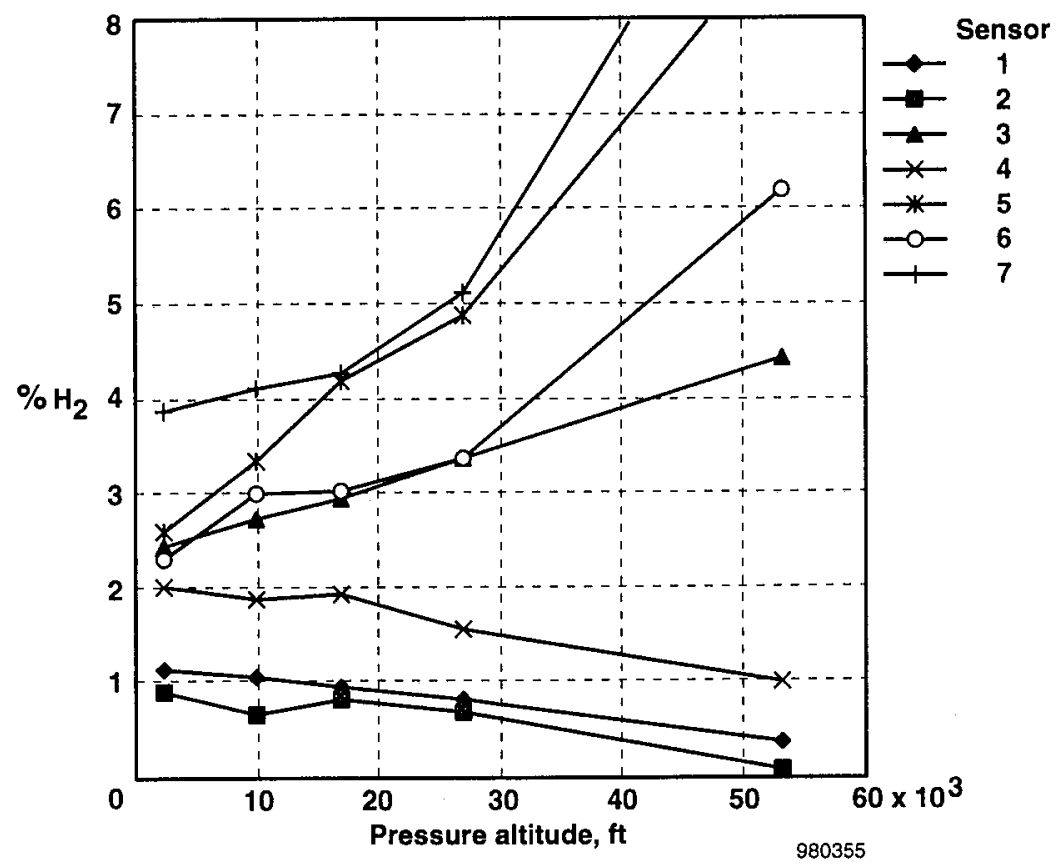

(b) Pressure altitude compared with percent $H_{2}$, for 3 percent $H_{2}$ mixture.

Figure 9. concluded.

\section{Fire Detection and Pod Temperature Thermocouples}

Fifteen thermocouples were distributed throughout the pod for sensing heat from nearby combustion. Thermocouples are commonly used for local fire detection. Procedurally, if high temperatures that were far above expected ambient total temperatures were seen (especially locally), fire would be indicated and steps would be taken to dump the propellants and secure the aircraft.

The thermocouples were also used to monitor pod environment temperatures, because certain components were temperature limited, such as the composite $\mathrm{H}_{2}$ tanks and electronics. Flight data (fig. 10) showed that, except for some areas near cryogenic components, the pod thermal environment was quite benign throughout the mission profile. During ground operations and in flight up to Mach 1.6 and an altitude of $50,000 \mathrm{ft}$, temperatures typically ranged from $45^{\circ} \mathrm{F}$ to $85^{\circ} \mathrm{F}$. This benign environment was unexpected, given the wide range of external static and total temperatures throughout the mission. If pod temperatures had approached the $\mathrm{H}_{2}$ tank temperature limit of $130^{\circ} \mathrm{F}$, steps would have been taken to cool the pod by decelerating the aircraft or turning on the water mist. If these measures had not been successful, the $H_{2}$ tanks would have been depressurized by dumping the contents overboard.

\section{Water Misting and Coolant System}

The coolant water system was used to provide a cooling water mist for the pod, and to recirculate coolant for the electronics. The recirculating coolant was required anytime the pod was powered up. The mist was to be turned on only when necessary and appropriate for pod cooling, such as during high stagnation temperature flight conditions

Figure 11 shows a schematic of the system. About 20 gallons of water was carried aboard the SR-71. The recirculating coolant flow rate was 3 gallons per minute $(\mathrm{gpm})$, and the mist flow rate was $0.18 \mathrm{gpm}$. The water was chilled by cold air from the SR-71 environmental control system. It was important to verify that the $\mathrm{N}_{2}$ purge was on before turning on the water mist, to prevent moisture from entering the electronics boxes. Figure 12 shows the altitude and temperature regimes where the water mist boils into vapor; condensing water was undesirable, because it could cause hardware problems. The upper temperature limit for the composite high-pressure tanks is also indicated. Clearly, the usable range for water mist is limited if 

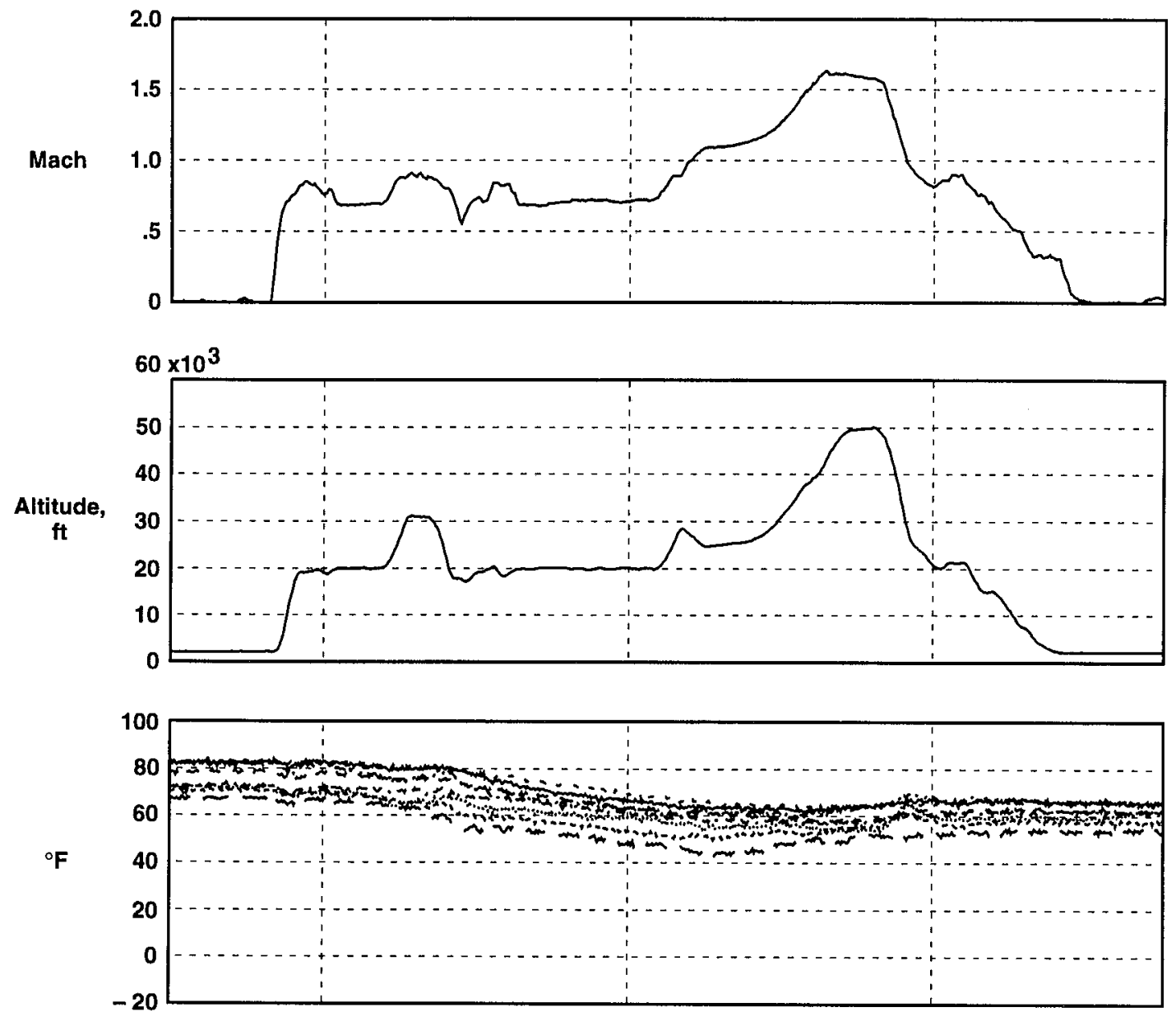

Canoe thermocouples

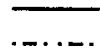

- - -

…

- - -

- -

-.....

………….....

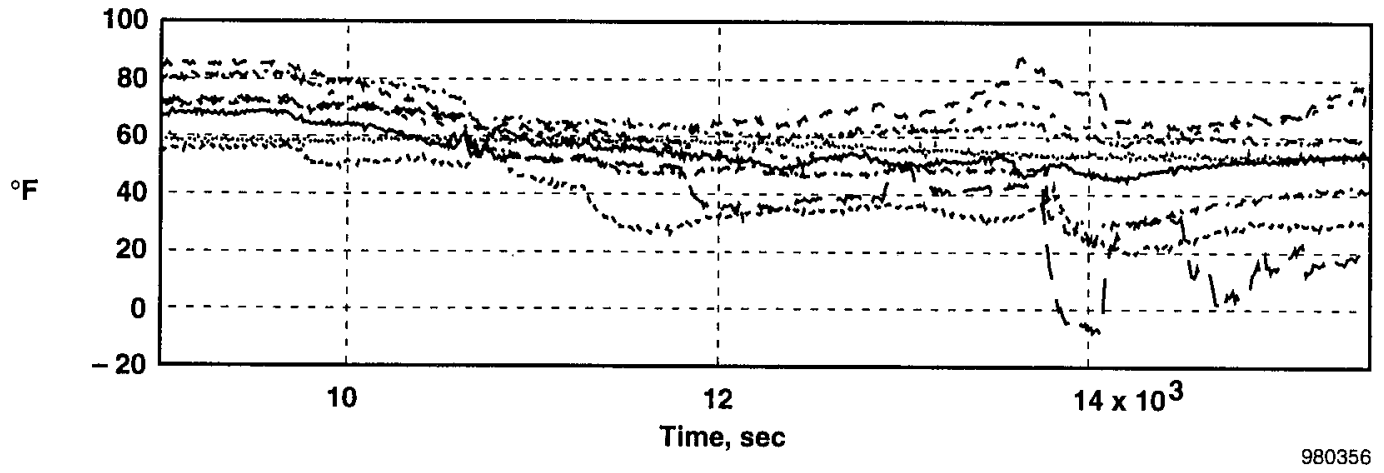

Model thermocouples

.....

- - -

...

$--\cdot$

- -

.......

..................

Figure 10. Pod in-flight thermal environment, up to Mach 1.6 and an altitude 50,000 ft. 


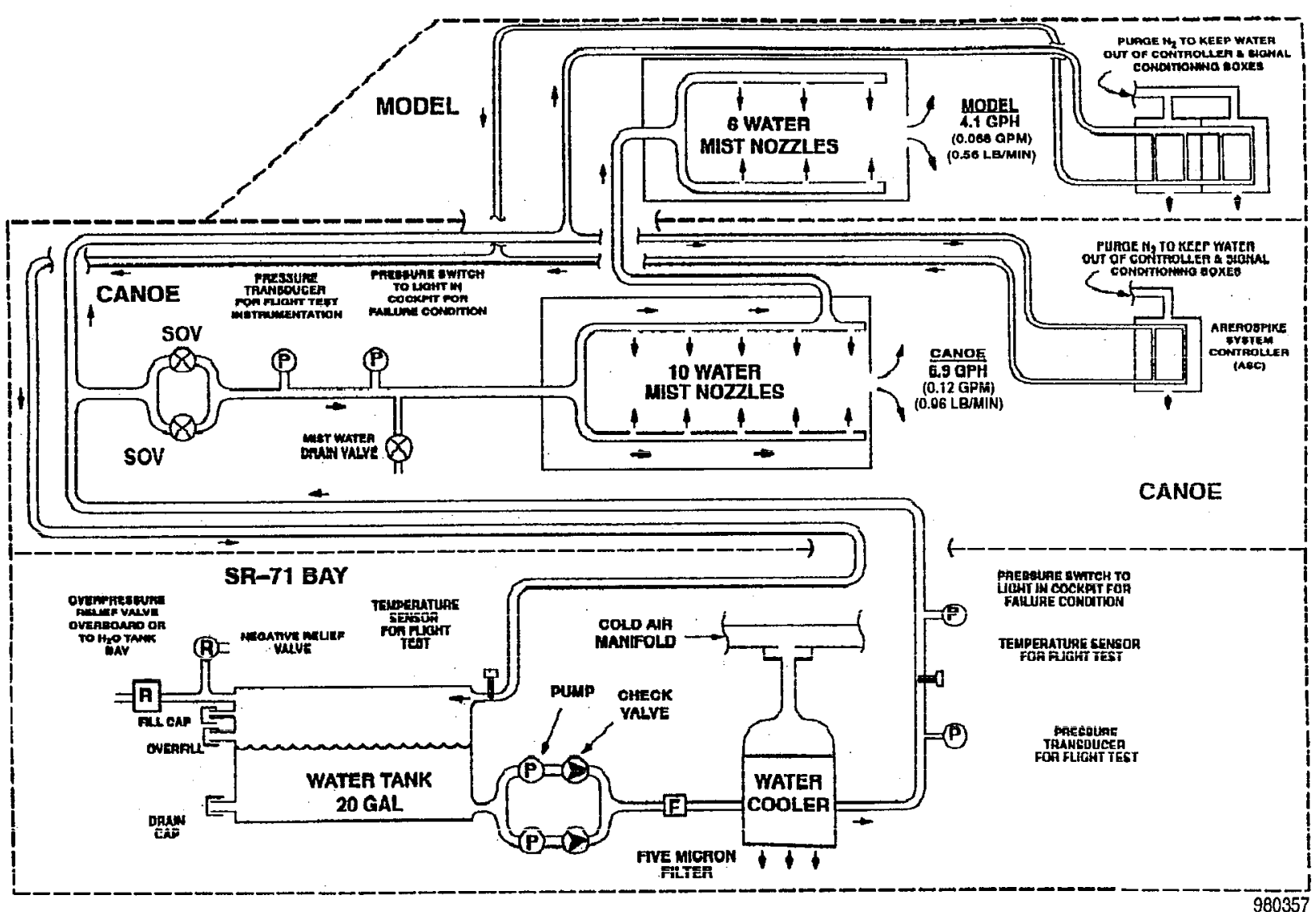

Figure 11. Pod water-misting and coolant system schematic.

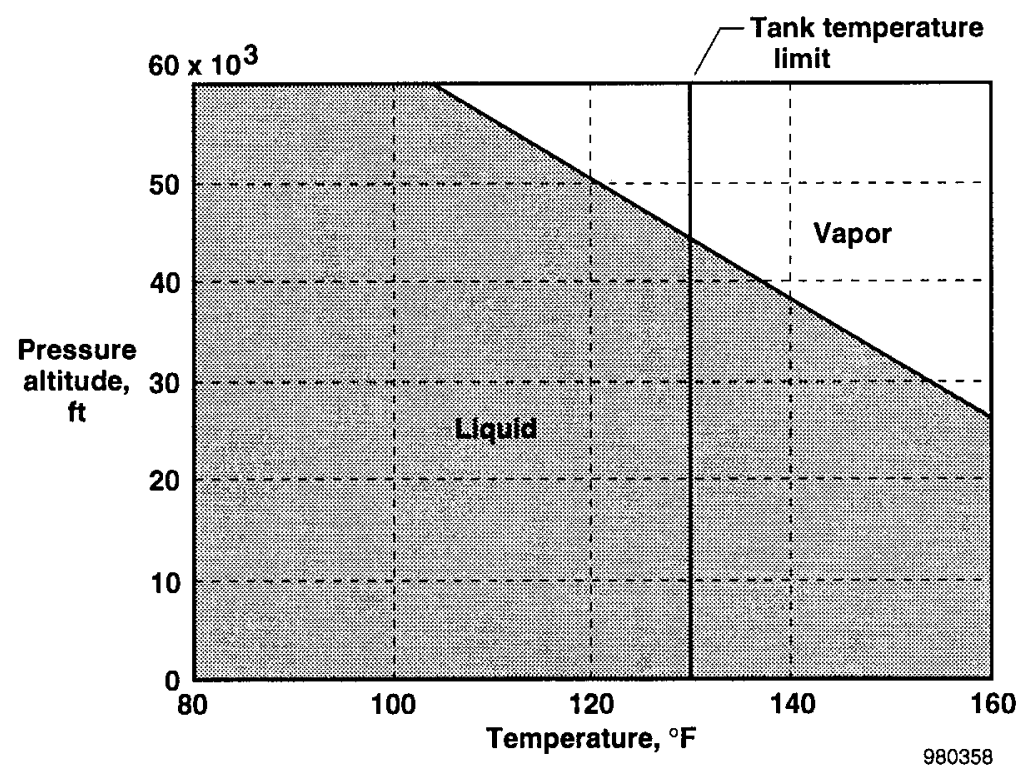

Figure 12. Pod water-misting envelope, pod temperature compared with pressure altitude. 
condensation is to be avoided. Also, water mist was not for use as a fire suppressant, and could aggravate electrical fires.

The original dual coolant pumps experienced repeated failures, because they were not designed for continuous service. These pumps were replaced with a more robust single pump. In practice, the water mist system was never used in flight because additional cooling was not necessary and because there were concerns about hardware damage from water condensation.

\section{Control Room Displays}

Propulsion systems and fire hazard mitigation system parameters were monitored in real time using control room displays. Two displays (not shown) were dedicated to monitoring propulsion system parameters and general system health. These displays schematically represented the propellant feed systems, and were used for decision making during tests and missions. Additional displays and strip charts showed more detailed and time history data of specific parts of the propulsion and fire hazard mitigation systems.

One display was primarily used for monitoring of the fire hazard mitigation systems and parameters (fig. 13). This display included: a time history plot of the $\mathrm{H}_{2}$ leak detection algorithm; bar charts and digital values of the fire detection thermocouples and $\mathrm{O}_{2}$ sensors; and digital indicators of $L N_{2}$ purge and water misting and coolant systems. The operator of this display could easily switch to time histories of the fire detection, thermocouples, $\mathrm{O}_{2}$ sensors, or $\mathrm{H}_{2}$ sensors by selecting the appropriate on-screen button. A keyboard interface allowed real-time setup and resets of the leak detection algorithm. All critical parameters changed from green,

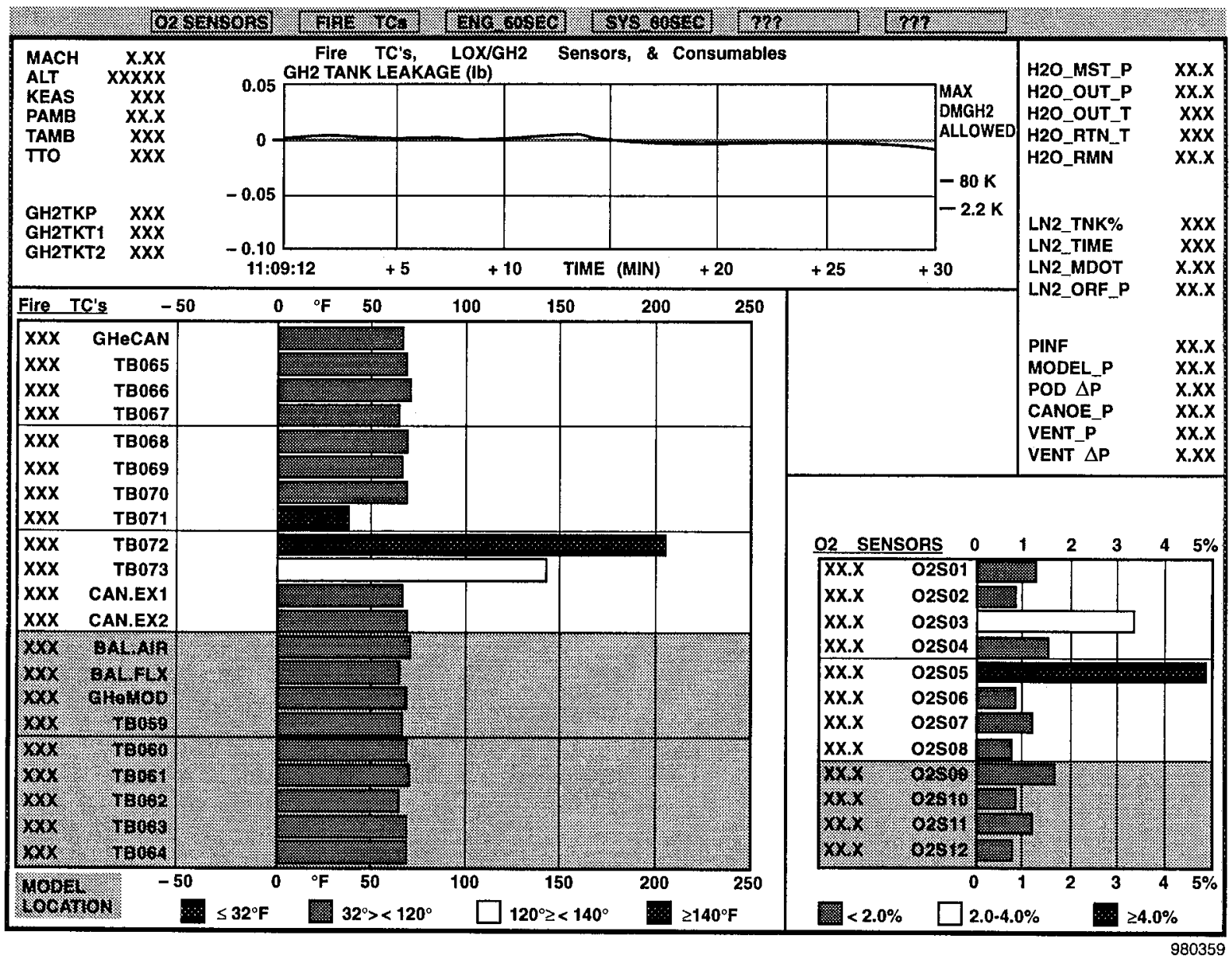

Figure 13. Primary control room display for fire hazard mitigation systems. 
to yellow, then red, as they approached and then exceeded predetermined limits.

Ground tests and inert flight tests helped validate and mature the control room displays and operating procedures. Control room displays, although they may appear overly detailed, proved indispensable during the extended development and troubleshooting program, and for determining system status and performance.

\section{Conclusions}

The LASRE experiment incorporated a number of propulsion hazard mitigation systems. Hazards were mitigated by minimizing or detecting the three ingredients essential to the production of fire: fuel, oxidizer, and ignition source. The major findings were as follows.

For inert purge of the vehicle cavity, it was important to provide an adequate purge flow rate and to seal the vehicle well against outside air infiltration. Those efforts reduced the in-flight cavity $\mathrm{O}_{2}$ levels from nearly 21 percent to below 4 percent.

Oxygen and hydrogen sensor accuracies in flight needed to be considered. Accuracy in terms of volume fraction-of-gas degraded at high altitudes. This was because the sensors actually measured partial pressure of the gas. For a given volume fraction-of-gas, as altitude increased, ambient pressure decreased, and the partial pressure of the gas also decreased, approaching sensor accuracy limits. Sensor accuracy could be better characterized by calibration at reduced pressures. Oxygen sensors were a mature technology and were value-added for safety monitoring. Accurate and robust hydrogen sensors able to operate in an inert flight environment were identified as an important safety technology, requiring further development.

A pressure- and temperature-based gaseous propellant tank leak-detection algorithm was found to be a useful tool, but could not be relied upon to detect all hazardous leaks. This algorithm could detect moderate to large tank leaks, or smaller leaks over a long period of time. However it could not detect small, but still hazardous, leaks in a timely manner, nor did it detect leaks in the $\mathrm{H}_{2}$ lines or during flow.

The pod thermal environment was found to be surprisingly benign throughout the mission, up to
Mach 1.6 and an altitude of $50,000 \mathrm{ft}$, given the wide range of static and total temperatures. The water mist system was never used in flight, because additional cooling was not necessary, and because of concerns about hardware damage from water condensation.

Detailed control room displays proved indispensable during the extended development and troubleshooting program, and for determining system status and performance.

\section{$\underline{\text { References }}$}

1"Safety Standard for Hydrogen and Hydrogen Systems," NASA NSS-1740.16, Office of Safety and Mission Assurance, Washington DC, 1995.

2"Safety Standard for Oxygen and Oxygen Systems," NASA NSS-1740.15, Office of Safety and Mission Assurance, Washington DC, 1996.

${ }^{3}$ Corda, Stephen, David P. Lux, Edward T. Schneider, and Robert R. Meyer Jr., "Blackbird Puts LASRE to the Test," Aerospace America, vol. 36, no. 2, pp. 24-29, Feb. 1998.

4"Standard General Requirements for Safe Design and Operation of Pressurized Missile and Space Systems," MIL-STD-1522A (USAF), May 1984.

${ }^{5}$ Benz, F. J. and P. L. Boucher, "Flammability Characteristics of Hydrogen/Oxygen/Nitrogen Mixtures at Reduced Pressures," in: Proceedings of the Workshop on the Impact of Hydrogen on Water Reactor Safety, vol. 3, M. Berman, ed., SAND-81-0661, vol. 3, 1981.

${ }^{6}$ Miller, S. L., K. L. Hughes, J. L. Rodriguez, and P. J. McWhorter, "Calibration and Characterization of Wide Range Hydrogen Sensors," in: Advanced Earth-to-Orbit Propulsion Technology Conference, CP-3282, vol. 1, Huntsville, AL, 1994.

${ }^{7}$ Hunter, Gary W., A Survey and Analysis of Commercially Available Hydrogen Sensors, NASA TM-105878, 1992.

${ }^{8}$ Hunter, Gary W., A Survey and Analysis of Experimental Hydrogen Sensors, NASA TM-106300, 1992. 


\section{REPORT DOCUMENTATION PAGE}

Public reporting burden for this collection of information is estimated to average 1 hour per response, including the time for reviewing instructions, searching existing data sources, gathering and maintaining the data needed, and completing and reviewing the collection of information. Send comments regarding this burden estimate or any other aspect of this collection of intormation,

including suggestions for reducing this burden, to Washington Headquarters Services, Directorale for Intormation Operations and Pep
VA 22202-4302, and to the Office of Management and Budget, Paperwork Reduction Project (0704-0188), Washington, DC 20503.

\begin{tabular}{|l|l|l|}
\hline 1. AGENCY USE ONLY (Leave blank) & $\begin{array}{c}\text { 2. REPORT DATE } \\
\text { July } 1998\end{array}$ & $\begin{array}{l}\text { 3. REPORT TYPE AND DATES COVERED } \\
\text { Technical Memorandum }\end{array}$ \\
\hline
\end{tabular}

4. TITLE AND SUBTITLE

July 1998

5. FUNDING NUMBERS

Linear Aerospike SR-71 Experiment (LASRE): Aerospace Propulsion

Hazard Mitigation Systems

\section{AUTHOR(S)}

WU 242-33-02-00-33-00-T15

Masashi Mizukami, Griffin P. Corpening, Ronald J. Ray, Neal Hass, Kimberly A. Ennix, and Scott M. Lazaroff

7. PERFORMING ORGANIZATION NAME(S) AND ADDRESS(ES)

NASA Dryden Flight Research Center

P.O. Box 273

Edwards, California 93523-0273

8. PERFORMING ORGANIZATION

REPORT NUMBER

9. SPONSORING/MONITORING AGENCY NAME(S) AND ADDRESS(ES)

10. SPONSORING/MONITORING

AGENCY REPORT NUMBER

National Aeronautics and Space Administration

Washington, DC 20546-0001

NASA/TM-1998-206561

11. SUPPLEMENTARY NOTES

Presented at the 34th AIAA/ASME/SAE/ASEE Joint Propulsion Conference, Cleveland, Ohio, July $13-15$, 1998.

Masashi Mizukami, Griffin P. Corpening, Ronald J. Ray, Neal Hass and Kimberly A. Ennix, NASA Dryden Flight

Research Center, Edwards, California; Scott M. Lazaroff, NASA Johnson Space Center, Houston, Texas.

\begin{tabular}{l|l}
\hline 12a. DISTRIBUTIONAAVAILABILTYY STATEMENT & 12b. DISTRIBUTION CODE
\end{tabular}

Unclassified-Unlimited

Subject Category 20

13. ABSTRACT (Maximum 200 words)

A major hazard posed by the propulsion system of hypersonic and space vehicles is the possibility of fire or explosion in the vehicle environment. The hazard is mitigated by minimizing or detecting, in the vehicle environment, the three ingredients essential to producing fire: fuel, oxidizer, and an ignition source. The Linear Aerospike SR-71 Experiment (LASRE) consisted of a linear aerospike rocket engine integrated into one-half of an X-33-like lifting body shape, carried on top of an SR-71 aircraft. Gaseous hydrogen and liquid oxygen were used as propellants. Although LASRE is a one-of-a-kind experimental system, it must be rated for piloted flight, so this test presented a unique challenge. To help meet safety requirements, the following propulsion hazard mitigation systems were incorporated into the experiment: pod inert purge, oxygen sensors, a hydrogen leak detection algorithm, hydrogen sensors, fire detection and pod temperature thermocouples, water misting, and control room displays. These systems are described, and their development discussed. Analyses, ground test, and flight test results are presented, as are findings and lessons learned.

\section{SUBJECT TERMS}

Fire prevention, Flight safety, Hypersonic vehicles, Reusable launch vehicles, Rocket engines

\begin{tabular}{|l|l}
\hline 17. SECURITY CLASSIFICATION & 18. SECURITY CLASSIFICATION \\
OF REPORT & OF THIS PAGE \\
Unclassified & Unclassified \\
\hline
\end{tabular}

Unclassified

15. NUMBER OF PAGES

22

16. PRICE CODE

$\mathrm{A} 03$

20. LIMTTATION OF ABSTRACT

Unlimited 